Bernardo Estellita Lins

Doutor em economia pela UnB. Consultor legislativo da Câmara dos Deputados na área de ciência e tecnologia, comunicação e informática. E-mail: bernardo. lins@camara.leg.br.

\section{Mídia digital e formação da preferência eleitoral}

\author{
Digital media and electoral \\ preference formation
}

Medios digitales y formación de preferencias electorales 


\section{RESUMO}

Este artigo compila conjecturas que já se encontram disponíveis a respeito da condução de campanhas eleitorais vitoriosas nos últimos anos. Examina-se a transição no uso da mídia, buscando descrever os mecanismos subjacentes ao uso eficiente das redes sociais. Um modelo descritivo é esboçado, tentando incorporar alguns aspectos de operacionalização de campanhas. Busca-se explicar como a relação entre equipes de campanha, consultorias especializadas em análise de dados e provedores de aplicação tornou-se um ativo essencial para uma comunicação de campanha eleitoral bem operacionalizada.

Palavras-chave: Eleições majoritárias. Escolha racional. Internet. Mídias sociais.

\section{ABSTRACT}

The use of social media in recent elections is examined, through a compilation of conjectures advanced by other authors on the management of winning campaigns. The transition to the use of social networks is discussed. A descriptive model is introduced, in order to examine how campaigns are carried out. We advance an explanation on how the interaction between campaign committees, consulting firms in data analysis and application providers is becoming an asset for a proper campaign communication.

Keywords: Majority elections. Rational choice. Internet. Social media.

\section{RESUMEN}

Este trabajo compila algunas reflexiones que ya se desarrollan acerca del modo de conducir campañas electorales en los últimos años. Se examina la transición en el uso de los medios, buscando describir algunos mecanismos subyacentes al uso eficiente de las redes sociales. Se esboza un modelo descriptivo, intentando incorporar aspectos operacionales de campañas electorales, para explicar de cual forma la relación entre comités, equipos de análisis de datos y proveedores de aplicaciones se transforma en un activo primordial para una comunicación efectiva. Palabras claves: Elecciones mayoritarias. Acción racional. Internet. Redes sociales.

Submissão: 2-10-2018

Decisão editorial: 19-6-2019 


\section{Introdução}

O modelo de comunicação eleitoral pelas mídias sociais na internet e em smartphones vem sendo adotado por candidatos mundo afora, tendo sido relevante, no Brasil, para as vitórias de João Dória à prefeitura de São Paulo, em 2016, e de Jair Bolsonaro à Presidência, em 2018. Trata-se de uma forma inovadora de conduzir a campanha política e há conjecturas de que seja um fator determinante de vitórias eleitorais que desafiam as avaliações prévias conduzidas pelos institutos de pesquisa.

Mudanças na abordagem midiática de campanhas são recorrentes na história das eleições. Em outubro de 1960, o debate entre John F. Kennedy e Richard Nixon, durante a campanha presidencial norte-americana daquele ano, marcou a história da comunicação de massa. Foi o primeiro debate transmitido ao vivo pela televisão e, segundo Casswell (2002, p.96), teria mudado os rumos daquela disputa, que Kennedy venceria no mês seguinte com uma estreita margem de vantagem, de apenas $0,2 \%$ dos votos.

No debate, Kennedy apresentou-se bem preparado, maquiado, num elegante terno claro, comunicando-se com desembaraço, diante de um Nixon cujo olhar aparentava o previsível cansaço da campanha. Aqueles que ouviram o debate pelo rádio preferiram 
as posições de Nixon, mas quem assistiu o confronto pela televisão deu inegável vitória ao jovem candidato democrata. A vitória de Kennedy foi interpretada como uma demonstração contundente do potencial da televisão para mudar a percepção do público (JOHNSON, 2018, p. 53, 55-56).

Anos depois, a tevê continuava a ser um veículo influente e poderoso. Se em 1960 iniciou-se o domínio da televisão nas campanhas eleitorais nos EUA, essa tendência demoraria mais alguns anos para consolidar-se em outros países. No Brasil, as eleições de 1989, as primeiras após o período militar, vencidas por Fernando Collor de Mello, marcaram o início da preponderância da televisão como ferramenta eleitoral (BOAS, 2005, p. 33-34).

Nas duas décadas deste século, com a consolidação das redes sociais, dos blogs e dos aplicativos de conteúdo, a estrutura econômica e a relevância sociopolítica da mídia tradicional entraram em declínio. Na maior parte dos países, a imprensa perdeu títulos e leitores, o rádio especializou-se como um veículo de nicho, a televisão aberta vem sendo suplantada pelos canais por assinatura e estes, por sua vez, veem seu mercado ser corroído pelas aplicações over-the-top (OTT), que oferecem conteúdo por demanda pela internet. A comunicação social foi transformada (DIMMICK et al, 2004: 26; JONES e WEST, 2017, p. 576-577).

A eleição presidencial de 2008 nos EUA, vencida por Barack Obama, foi o primeiro pleito de destaque global em que foi adotada uma nova forma de fazer política, exigida pelo mundo das redes sociais. Na sua primeira campanha à presidência, Obama era um jovem senador de primeiro mandato, com dez anos de 
vida pública. Venceu, ainda assim, as primárias democratas contra Hillary Clinton, tida como favorita, e a eleição presidencial contra John McCain, político com mais experiência, herói de guerra e personalidade de grande respeito. Oriundo da elite, embora de minoria negra e filho de estrangeiro, Obama estudou em Columbia e doutorou-se em Harvard. Tinha qualidades de político tradicional, entre as quais vários autores destacam sua oratória e sua visão estratégica. O diferencial da sua campanha, em termos de comunicação com o público, foi a adoção de técnicas e táticas relacionadas ao mundo da internet, especialmente como mecanismo de arrecadação de doações e de divulgação de propaganda (BIMBER, 2014, p. 134-135; GOMES et al, 2009, p. 29-30, 34; HENDRICKS e DENTON, 2010, p. 7-9; JAGDEV et al, 2016, p. 119).

Oito anos mais tarde, a campanha do candidato republicano Donald Trump à presidência dos EUA levaria a eficácia desses instrumentos de comunicação via internet a um novo patamar. Trump era tido como um azarão que derrotou, um a um, os demais postulantes do Partido Republicano e, finalmente, a candidata democrata, novamente Hillary Clinton. Com uma campanha recheada de controvérsias e um discurso marcado por extrema agressividade, defendeu um projeto de uma nação americana mais fechada, mais conservadora e mais centrada na defesa de interesses internos, solidificando um apoio no rust belt, faixa da região dos Grandes Lagos e do meio-oeste norte-americano marcada pelo declínio econômico e por índices elevados de desemprego. No entanto, um aspecto que chamou a atenção de analistas foi o uso intenso das redes sociais, em especial o programa Twitter, como base de elaboração midiática do 
candidato. As raízes desse modo de fazer campanha, no entanto, são mais profundas e envolvem um uso intenso da computação, com efeitos importantes na estratégia seguida pela equipe de campanha (PERSILY, 2017, p. 65, RODRÍGUEZ-ANDRÉS, 2018, p. 839).

Também fizeram uso desse ferramental os empreendimentos eleitorais de Mauricio Macri, na Argentina, e de vários candidatos nas eleições gerais de países europeus nos últimos dois anos, entre os quais Emmanuel Macron e Marine Le Pen na França. Também se apoiaram no uso de mídias sociais campanhas que não venceram eleições, mas mantiveram fôlego competitivo, como a de Bernie Sanders nas primárias democráticas de 2016 (CHADWICK e STROMER-GALLEY, 2016, p. 285-287). Nas eleições presidenciais brasileiras de 2018, seu uso se generalizou, em especial pelos candidatos ligados à coligação vencedora.

Este texto busca examinar as diferenças entre as formas de conduzir a comunicação de campanhas eleitorais típicas do século XX, em especial pela televisão aberta, e as modalidades de campanha que estão se consolidando nos últimos dez anos, com o uso da internet. Para isto, está construído como segue. Na seção 2, faz-se uma revisão da literatura de escolha racional, à qual o artigo se afilia. Na seção 3, são apresentados alguns comentários sobre a forma convencional de campanha típica do século passado, apoiada na formação da opinião pública pelos meios de comunicação eletrônica de massa, para contextualizar a diferença com a lógica subjacente ao uso de mídias sociais. A seção 4 é destinada à apresentação de alguns elementos da condução segmentada de uma campanha, típica das eleições 
mais recentes. Discute-se brevemente, ainda, o fenômeno das fake news. E a seção 5 discute os efeitos estruturais e institucionais e faz alguns apontamentos sobre o poder dos provedores de aplicações são introduzidos. Apresentam-se, enfim, as conclusões.

\section{o sentido do discurso político}

\section{Comportamento racional do eleitor}

Este artigo busca situar-se no contexto da literatura de escolha racional do eleitor. Trata-se, como aponta Kousser (2001, p. 22), de uma linha de reflexão de longa tradição, que tem início no extenso livro de Key (1949) sobre a política no Sul dos EUA. O autor, um notável estudioso da ciência política, abre a possibilidade de uma análise unidimensional do pleito eleitoral, ao postular que a política em geral se reduz, no longo prazo, a um conflito entre os abastados e os que possuem menos e que, na política estadual, os temas cruciais tendem a se ajustar a aspectos de gastos públicos e de aplicação de impostos, ou seja, de quanto se está disposto a oferecer de serviços à sociedade e de sobre quem recairá o peso do custeio desses serviços. Nesse sentido, a organização do aparato governamental é indispensável para conduzir essa redistribuição e o debate sobre essa redistribuição é um aspecto chave do pleito, ao qual os demais temas fazem referência (KEY, 1949, p. 307-308, 311, 644-645).

As contribuições de Anthony Downs, congruentes com essas intuições, estabeleceram a fundamentação para os modelos de escolha racional, limitando a análise ao problema de dois candidatos ou partidos competindo pelo eleitorado e maximizando alguma forma de benefício político ou econômico represen- 
tado em uma dimensão (DOWNS, 1957, p. 143-144). Ambos declaram simultaneamente sua plataforma e o eleitorado escolhe um destes. Assume-se que o vencedor implementará a posição política prometida, aderindo ao compromisso assumido. Uma ampla discussão desse tipo de modelo e de suas variantes é oferecida em Persson e Tabellini (2000, p. 48-58).

Figura 1 - Representação de um modelo unidimensional de escolha política

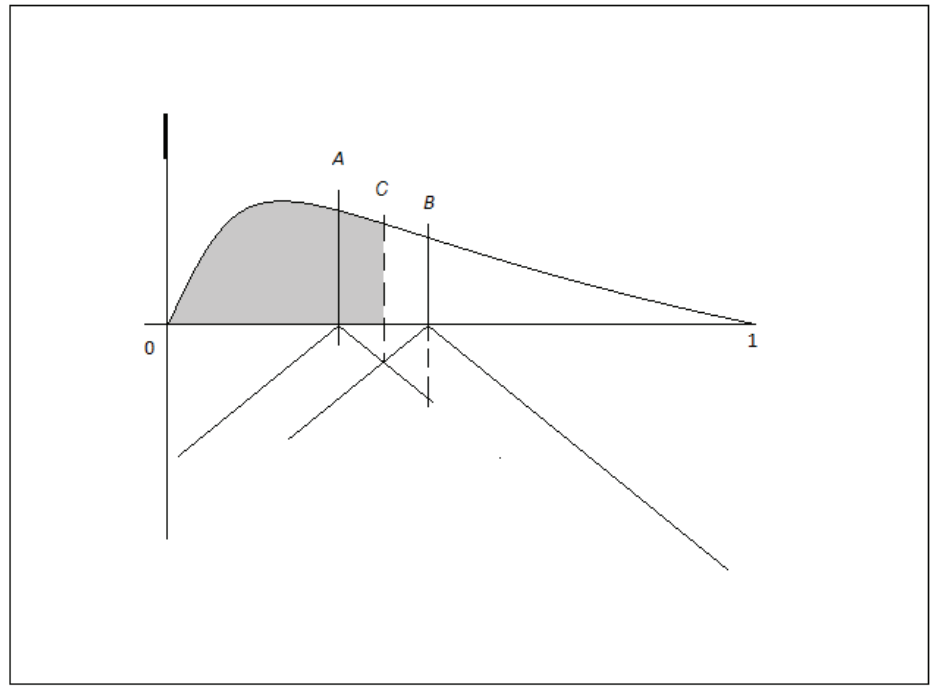

Kousser (2001, p. 29-32) apresenta uma abordagem gráfica simplificada à la Hotelling (figura 1), que pressupõe que o eleitorado $\varepsilon$ esteja distribuído ao longo de uma dimensão linear $x$, que vai da extrema esquerda $(x=0)$ à extrema direita $(x=1)$. A distribuição é contínua e satisfaz as características de uma função de distribuição de probabilidades, em particular a da área sob a curva ser igual a 1.

O eleitor que se situa precisamente na posição correspondente à plataforma declarada por um can- 
didato A tem exatamente sua preferência atendida. Os demais eleitores, por exemplo, nas posições $B$ e $C$, incorrem em uma perda (uma desutilidade) para votar no candidato, que cresce linearmente com a distância entre a plataforma de A e suas preferências individuais.

Se um segundo candidato situa sua plataforma em uma posição política $B$, o processo se repete. Na figura 1, um eleitor situado em $C$ é indiferente às duas plataformas e delimita a parcela do eleitorado que irá votar em cada um dos dois candidatos.

O modelo de escolha racional acima descrito, apesar de sua simplicidade, envolve premissas fortes, que merecem ser apontadas, para que a discussão da validade dos resultados esperados possa ser adequadamente levada adiante. O caráter unidimensional da escolha política é crucial ao modelo e representa um processo de sinalização política, que será comentado a seguir.

O discurso do candidato, quando examinado em detalhe, alcança um grau de complexidade maior do que o capturado no modelo. Adota formatos e estratégias distintas, conforme a abordagem escolhida para se chegar ao público. Em uma campanha, o candidato dialoga com uma variedade de agentes e interesses, que podem ser ordenados conforme diversos critérios.

O objetivo final de um candidato é colocar sua mensagem junto ao eleitor, de modo a assegurar o voto. Isto pode ser feito diretamente, por exemplo batendo de porta em porta, sentando nas mesas dos bares, conversando nas feiras livres ou subindo em uma caixa de laranjas para discursar na praça. Os 
resultados dessas iniciativas tendem a ser irrelevantes no cômputo eleitoral.

A forma eficaz e convencional de chegar diretamente ao eleitorado é a cobertura de mídia, seja jornalística, seja publicitária. Os meios de comunicação de massa propiciam a escala e o acesso que permitem com que a mensagem do candidato alcance, em um prazo compatível com o ciclo eleitoral, o número de pessoas suficiente para promover a construção de uma massa de eleitores que o apoie e viabilize um resultado favorável. Esta é, precisamente, a modalidade de interlocução tradicional na política do século $X X$ '.

No entanto, há intermediações que dão eficácia à compreensão e aceitação do discurso. Entre estas, é recorrente a menção ao papel político e comunicacional do que se convenciona chamar de sociedade organizada. É o segmento do público que possui interesses bem delimitados, cujo atendimento é determinante do voto. Há instituições que de alguma forma congregam esse público ou interagem com ele, seja por representar alguns de seus interesses

A mídia eletrônica de massa (rádio e televisão) não descarta o uso de outras formas de comunicação até o eleitor, como mídia impressa, panfletos, eventos públicos de grande porte ou propaganda boca a boca da militância. Em eleições distritais sem obrigação de comparecimento, como é o caso das eleições de deputados nos EUA, a importância da interação do candidato com a comunidade e da eficiência de seu comitê de campanha são centrais à sua competitividade, privilegiando o candidato incumbente. No entanto, apontam Goidel e Shields (1994: 806-807), a exposição na mídia é central para a credibilidade dos candidatos, em especial se forem independentes. Em eleições majoritárias, porém, o alcance da mídia eletrônica e sua permeabilidade pelos vários segmentos da população são mais significativos para dar eficácia à campanha. 
ou crenças (por exemplo, entidades de lobby), seja porque proveem o ambiente para a condução de atividades não políticas, mas que podem ser diligentemente utilizados na campanha (por exemplo, sindicatos, entidades caritativas ou de trabalho voluntário, grupos de estudo, comunidades religiosas). O acesso do candidato às entidades da sociedade organizada possibilita o uso dessas instituições de representação como intermediários.

Outra interface usualmente considerada é representada pelas instituições da classe política, cuja função é filtrar o debate dos interesses esparsos da população e dos grupos de interesse, para dar-lhes uma roupagem ordenada. Tradicionalmente, o partido político é a instituição que cristaliza essa dimensão, que estabelece uma narrativa agregadora, capaz de fazer convergir a imagem do candidato com o conjunto de demandas da sociedade organizada e da população em geral².

Em certo sentido, o partido cumpre, na escolha política, o papel de sinalização que a marca cumpre na escolha de consumo. Aponta as características distintivas do discurso do candidato e demarca uma diferenciação com os adversários. Essa linha de clivagem é importante porque estabelece mecanismos de identificação do eleitor com a mensagem e de fidelização do seu voto.

Um recurso adicional, explorado, sobretudo pelo candidato incumbente que se expõe à reeleição, relaciona-se com a função operacional do governo, que implementa políticas públicas distributivas, beneficiando certas instituições ou grupos de interesse, e

2 Ver, por exemplo, nesses aspectos, a interessante discussão de Rennó (2006: 54-56). 
conduz um esforço publicitário dessas iniciativas, mais uma vez fazendo uso da máquina de produção de sentido da mídia ou das redes sociais.

O discurso político não é meramente informativo. Faz apelo às várias formas de recepção e interpretação do público, tendo diversas funções. Os modelos de escolha racional enfatizam a função contratual do discurso, ou seja, a declaração de uma plataforma que será levada adiante após a eleição pelo candidato vencedor. Presume-se que essas declarações sejam vinculantes e, nos casos em que são sumariamente abandonadas, a sensação de "estelionato eleitoral" acaba por prevalecer, ou passa a ser sistematicamente explorada por adversários políticos.

Para que o discurso de função contratual seja bemsucedido, precisa de um ambiente favorável de recepção e de um processo de disseminação abrangente.

O ambiente favorável de recepção envolve a empatia com o candidato, a compreensão do seu linguajar e o encaixe dos seus valores na estrutura de pensamento do público. Essa preparação é tipicamente construída pelos mecanismos de formação da opinião pública e resulta de ações, deliberadas ou não, conduzidas antes que o candidato procure o eleitorado.

A disseminação da mensagem, por sua vez, requer, cumulativamente, que esta seja recebida, compreendida e aceita. Pode, igualmente, fazer uso de ações de mídia, e ocorre no momento em que o candidato procura interagir com seu potencial eleitorado.

Em ambos os processos, as funções de legitimação e de sedução no discurso do candidato mostram-se centrais. A legitimação consiste no "casamento" entre a história do candidato ou do partido 
e as declarações de campanha. Esse encaixe intertemporal é uma garantia, ainda que fraca, de que o candidato, se vencedor, virá a efetivamente implementar a política prometida. Já a sedução consiste na construção de uma relação pessoal entre a imagem do candidato e cada eleitor em particular. Essa projeção da imagem, de início elaborada em eventos públicos e peças retóricas, é trabalhada pelas mídias para induzir, em cada eleitor, uma identidade com aspectos de apresentação visual, expressão verbal e não verbal, coincidência de valores e outros elementos de caráter emocional aderentes ao candidato ${ }^{3}$.

Uma função de agregação do discurso, enfim, busca dar organicidade à militância de apoio e delimitar sua atuação na campanha e, no caso de vitória, no encaminhamento da administração. Isto é realizado por diversas narrativas. A primeira é a de encaixe das demandas heterogêneas em uma construção ideológica e valorativa. A segunda é a de definição de prioridades da agenda, ordenando o contrato com o eleitor. A terceira é a da colocação do eleitor ou do membro do comitê de campanha em uma trajetória de eventos que constroem a convergência ao momento do voto, definindo um espaço de participação.

Formação da opinião pública, cultura de massa e campanha

A mídia é tradicionalmente considerada um agente formador da opinião pública e, como tal, capaz de afetar profundamente a percepção da

3 Alguns desses aspectos estão detalhados de modo bastante preciso em Bezerra e Silva (2006). 
sociedade quanto aos seus problemas, prioridades e formas de organização. O grau de influência da mídia em geral sobre a opinião pública tem sido objeto de alongada especulação acadêmica. Os efeitos da sua ênfase ou de seu silenciamento a respeito de temas importantes têm sido amplamente examinados, tanto em termos de modelagem abstrata como de exame de seguidos episódios.

O exame detalhado dessa literatura escapa aos objetivos deste artigo, mas excelentes compêndios fazem seu registro minucioso, como Graber (2000). Um dos aspectos que mais preocupam o teórico da comunicação diz respeito aos efeitos da estrutura empresarial da mídia sobre o conteúdo veiculado. Diversos trabalhos (COHEN, 1997; BAGDIKIAN, 2000; MORAES, 2000; HUNTEMAN, 2003), partindo de dados que sugerem uma acentuada concentração de mercado, conduzem uma análise sobre o comportamento das firmas de mídia, concluindo em geral com uma apreciação pessimista dos efeitos que podem ser esperados sobre a liberdade de expressão, a isenção da imprensa e o reforço dos valores democráticos.

Interessa apontar que, ao longo do século XX, a mídia eletrônica tradicional, rádio e televisão, respondeu pelo papel de formador de opinião pública mediante uma relação com o ouvinte ou o espectador em que este se colocava no polo passivo da relação midiática, recebendo a programação e aceitando as notícias e a publicidade que a acompanhavam. A ilustração da família sentada à mesa de jantar ou no sofá do living, assistindo hipnotizada ao programa televisivo, repetida em inúmeros filmes de época, descreve com propriedade o comportamento que então se constatava. $O$ espectador se integrava a um vasto 
conjunto de entes passivos, compondo a massa a ser manipulada pela mídia.

Os canais de rádio e tevê organizavam (e ainda organizam) sua programação para maximizar a audiência, reforçando preferências que, em média, já se encontravam presentes na população massificada. Essa audiência é "vendida" ao anunciante, que "compra" a expectativa de atenção do espectador ao espaço publicitário ou a uma ação de merchandising inserida na programação. Esta é a principal fonte de receita do veículo.

As pesquisas de audiência e de opinião são um elemento indissociável desse modelo, pois estabelecem os números que servem de base à escolha da programação e à cobrança de fees pela veiculação de publicidade.

A campanha eleitoral centrada no uso da televisão segue a mesma lógica. A mensagem do candidato é construída apontando para a preferência observada nas pesquisas de opinião, em busca de se acertar o eleitor mediano. As pesquisas dariam uma noção do nível de acerto das aparições do candidato, da propaganda eleitoral, da cobertura jornalística e dos programas eleitorais veiculados pela mídia.

A competição entre candidatos em um ambiente dominado pela cobertura de mídia tem um caráter que poderia ser chamado de binário. Os candidatos que recebem atenção alcançam de modo relativamente indiscriminado todos os espectadores, ou em outras palavras todo o eleitorado. E aqueles sobre os quais a imprensa silencia estão virtualmente alijados da disputa.

Esse processo é evidentemente muito mais complexo do que está sendo aqui descrito. Envolve ele- 
mentos de competição entre veículos, de alinhamento de interesses entre partidos e empresas de comunicação, de ética dos meios de comunicação no sentido de dar uma visão ampla e equilibrada do debate político ao seu público leitor, ouvinte ou espectador. Desse modo, há táticas para romper o silêncio da cobertura jornalística, ainda que de modo enviesado. Mas a informação, uma vez na imprensa e na mídia eletrônica, alcança o público de modo relativamente disseminado. No século XX, um público receptor passivo.

Portanto, modelos para tratar a decisão racional do eleitor, diante dos compromissos de natureza contratual expressados pelos candidatos, baseiam-se nessas premissas. $O$ eleitor, razoavelmente informado acerca das plataformas dos candidatos (função contratual), quantifica aquele que melhor poderia atender suas preferências. As demais funções do discurso legitimariam ou reforçariam a confiança desse eleitor nas promessas de campanha.

O modelo de escolha racional com uma única dimensão de política (esquerda-direita) explica que, diante desse comportamento, em uma eleição com dois candidatos, como é usualmente um segundo turno de uma eleição majoritária, haveria uma tendência de ambos os contendores no sentido de construir um compromisso e uma narrativa de "centro", ou seja, que coincidisse com a preferência do eleitor mediano. Desse modo, quem acertasse a posição desse eleitor teria assegurado o voto de pelo menos metade do eleitorado, mostrando-se uma alternativa vencedora.

Para os defensores de valores democráticos liberais, trata-se de um modelo que legitimaria o caráter 
participativo das eleições, reforçaria o confronto entre o candidato incumbente e seu opositor, ou seja, de quem estava "no cargo" ou "fora dele", garantiria um compromisso de centro e preservaria o papel dos partidos como intermediários da valoração ideológica e, posteriormente, como avalistas da governabilidade.

\section{Competição eleitoral pelas mídias sociais}

\section{Falhas no processo de construção da opinião de massa}

Nas eleições realizadas nos últimos anos, esse cenário descrito na seção anterior não se realizou. Em vários episódios (o plebiscito do Brexit, realizado no Reino Unido em 2016, é um exemplo), o resultado da votação não correspondeu à previsão das pesquisas de opinião. Usualmente, algumas explicações têm sido recorrentemente avançadas para explicar esse paradoxo.

A primeira é de que as pesquisas simplesmente estariam incorretas, por uma variedade de motivos: mudanças demográficas não identificadas que prejudicavam a delimitação da amostra e a estimação das margens de validade dos resultados, inadequação dos questionários em decorrência da mudança de cultura do eleitorado, constrangimento dos entrevistados diante de certas respostas e por aí vai.

A segunda é de que parte dos eleitores que prefeririam a opção que se mostraria perdedora teria deixado de comparecer ao escrutínio, também por várias possíveis razões: certeza antecipada da vitória, diferenças de comportamento em relação aos eleitores da outra parte, contaminação do pleito por outros fatores etc. 
E a terceira, de que mobilizações de última hora, a exemplo da pressão na "boca de urna", teriam um efeito suficiente para deslocar um resultado muito próximo de um empate.

Examina-se, aqui, uma quarta possibilidade, também intensamente discutida: a de que os mecanismos tradicionais de construção da opinião pública pela mídia foram suplantados pela divulgação de fatos e dados no âmbito de redes sociais. Se esta conjectura estiver correta, é preciso apontar qual o elemento informacional que tornou a rede social um mecanismo essencialmente diferente da mídia tradicional na formação da opinião pública. Em um enfoque da tecnologia subjacente à comunicação política, tal elemento é o uso de big data ${ }^{4}$.

\section{Uso de big data e construção de opinião fragmentada}

As aplicações de big data ${ }^{5}$ em eleições têm recebido ampla divulgação da imprensa nos últimos anos, pela variedade de casos de sucesso que vieram

4 É particularmente relevante, nesse aspecto, o projeto de pesquisa proposto por Ituassu et al, (2018) a respeito das eleições de 2018.

5 Big data é uma expressão que se refere a um conjunto de técnicas para a coleta e tratamento de grandes volumes de dados, com um objetivo de análise preditiva. Trata-se não apenas de operar sobre repositórios volumosos e complexos, com grande variedade de informações e formatos, mas também de fazê-lo com uma mentalidade exploratória e com uma flexibilidade de tratamento na busca de relações inesperadas entre esses dados. As ferramentas de big data não estão voltadas para dar a esses dados o tratamento para o qual foram coletados. O enfoque é justamente o oposto: coletar, construir e cruzar dados para obter informações ou insights para os quais esses dados não foram originalmente concebidos. 
a público. No Brasil, três episódios distintos receberam uma razoável divulgação à época de sua ocorrência, em 2016: o já citado referendo do Brexit, no Reino Unido, a campanha de eleição de Donald Trump à presidência dos EUA e a campanha de João Dória à prefeitura de São Paulo.

A estratégia usada nos três casos é semelhante, embora com níveis de refinamento de dados distintos. O episódio britânico, por ser mais antigo, serviu como excelente caso de referência para a adoção de big data na política. Sua eficácia baseia-se na tese de que é possível, a partir do comportamento de uma pessoa nas redes sociais, estabelecer algumas medidas acerca de seus traços psicológicos e sua personalidade. Trata-se de uma técnica de trabalho denominada psicometria.

O tratamento de big data ajusta-se a essa técnica ao possibilitar a coleta, o tratamento e a comparação de grandes volumes de informação a respeito das ações de uma pessoa na internet: a que redes sociais se conecta, que movimentos executa, quais as características de suas "curtidas", suas buscas, a frequência de suas mensagens e assim por diante (GRASSEGER e KROGERUS, 2017).

Observa-se que essas informações são comportamentais: não há quebra do sigilo de postagens ou uso de informações pessoais em sentido estrito. Ainda assim, a partir de informações tão superficiais, é possível chegar a medidas bastante precisas de traços da personalidade, tais como o quanto essa pessoa é extrovertida, perfeccionista, afável, emocionalmente equilibrada e aberta a novas ideias, cinco grandes componentes do seu comportamento, dimensões conhecidas como OCEAN (dos nomes em inglês, open- 
ness, conscientiousness, extraversion, agreeableness e neuroticism). Em uma abordagem convencional, essas dimensões seriam estimadas a partir de questionários bastante extensos. O "pulo do gato" foi dado por pesquisas na Universidade de Cambridge, no Reino Unido, que conseguiram correlacioná-las com resultados do comportamento das pessoas nas redes sociais (BACHRACH et al, 2012). Além disso, é possível derivar dessas informações, com relativa margem de segurança, uma variedade de atributos pessoais, como padrões de consumo, grupo socioeconômico a que pertence a pessoa, preferências políticas, afiliação religiosa ou opção sexual (KOSINSKI et al, 2013).

efeito das informações psicométricas no planejamento de campanhas eleitorais fez-se rapidamente sentir. Como os dados de acesso à internet estão, em muitos casos, disponíveis à comercialização, com um simples mascaramento das informações pessoais ("anonimização"), mas com a preservação de outros dados, a exemplo do georeferenciamento, tornou-se possível mapear comunidades quanto às suas preferências pessoais ou políticas, viabilizando um ajuste fino da abordagem ao eleitor. Esse mapeamento pode ser detalhado, em certas localidades, ao nível de quarteirão ou residência. Em certos casos, dados pessoais mantidos por outras fontes, como cartórios de registros de imóveis, licenciamento de veículos, filiação a clubes, cadastros de distribuidores de revistas ou operadoras de cartões de crédito, podem ser cruzados, para elevar a precisão do mapeamento. Nas eleições presidenciais de 2018 no Brasil, por exemplo, começam a surgir evidências de que foram utilizadas bases de dados de empresas financeiras e de telecomunicações, para acesso aos números de celulares de milhões de eleitores (ORTELLADO, 2018). 
A adoção dessas técnicas convulsiona a lógica convencional de condução de campanhas eleitorais. A visão tradicional, ligada ao uso da mídia eletrônica de massa como canal de informação do público e de eventos e convenções para mobilização partidária, parte de dois pressupostos que são rompidos: o de que há uma disputa ideológica entre plataformas partidárias e o de que cada eleitor recebe informações iguais às dos demais e se posiciona a favor da proposta que mais se aproxima da sua preferência política pessoal.

Nessa lógica convencional, como se comentou na seção anterior, os candidatos tenderiam a ajustar o discurso a uma posição capaz de angariar o maior número possível de eleitores, mantendo sua coerência interna. Em particular, em uma campanha com dois candidatos, como é o caso dos segundos turnos de campanhas eleitorais majoritárias, o ajuste do discurso se dá em busca da preferência do eleitor mediano, resultando em uma relativa convergência de propostas e em uma amenização do discurso político-ideológico em direção a uma posição de centro.

A ruptura dessa lógica convencional decorre do potencial oferecido pelas técnicas de psicometria e de segmentação dos dados, que possibilitam o mapeamento de características de personalidade e de preferências políticas em nível comunitário ou até individual.

A figura 2 descreve de modo sucinto o efeito da técnica. Ao dispor de dados psicométricos, a campanha de um candidato busca a posição precisa de cada eleitor em um espectro de características de personalidade (curva inferior da figura 2). Assim, em lugar de definir uma plataforma com uma mensagem 
voltada ao eleitor mediano, envia-se a cada eleitor um fluxo de mensagens fragmentadas, ajustadas a ele. Uma rede social ou um aplicativo de mensagens pessoais são os meios mais apropriados para essa comunicação personalizada. Assim, não existe a percepção de desutilidade: cada eleitor recebe exatamente o que deseja intimamente, em "pílulas". Esse fluxo de mensagens é assegurado pelo uso de robôs (os bots) que coordenam o envio das mensagens a partir de contas, códigos de usuários ou nomes de domínio fictícios ou criados apenas para esse fim (ver, por exemplo, FILER e FREDHEIM, 2016: 264).

Figura 2 - Do espectro ideológico à concentração de preferências

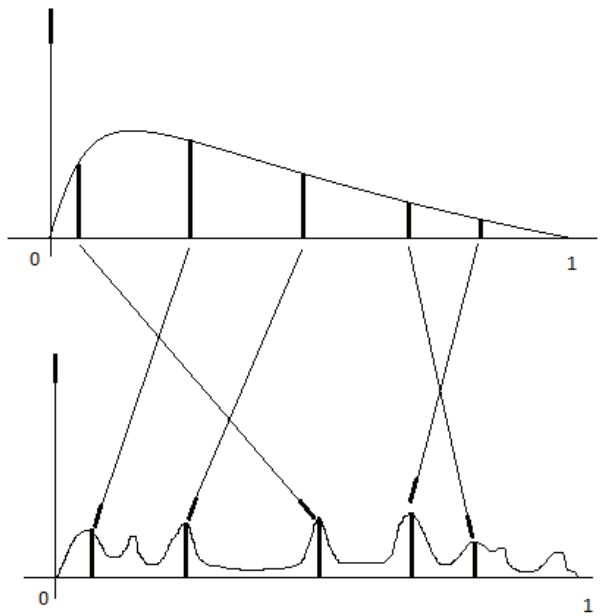

Espectro

político

esquerda-direita

Dimensão

emocional da

extroversão 
Na distribuição dos eleitores, segundo uma dimensão emocional, há pontos de concentração. Ao identifica-los, é possível refinar a comunicação política feita em veículos tradicionais, para atender essas parcelas de público com precisão. Na propaganda eleitoral pelos meios de comunicação de massa, deixa-se de lado a narrativa ideológica como fio condutor da plataforma, que privilegiaria uma única posição no espectro ideológico (lembre a figura 1) e passa-se a privilegiar a adoção de palavras-chave específicas, para realçar a identificação do candidato com esses interesses pontuais fortes. E o discurso do candidato reforça uma variedade de pontos muito focados, muitas vezes sem conexão aparente, que atendem ao sentimento dessas parcelas de público específicas. A comparação da dimensão emocional com o espectro político-ideológico, feita na figura 2, destaca o descasamento, segundo os dois critérios, entre as posições de eleitores selecionados.

Em certo sentido, a coesão narrativa que responde às funções de legitimação e agregação no discurso político perde relevância. Busca-se um contato virtual, direto e individualizado com cada um dos eleitores e a função de sedução torna-se crucial, investindo-se na espetacularização do candidato. O caso de Donald Trump é paradigmático (EDWARDS, 2018).

Um efeito curioso dessa estratégia é o de que os pronunciamentos públicos dos candidatos soam soltos e desconexos, ou que distintas aparições deles trazem mensagens contraditórias. A lógica interna do discurso político é sacrificada em nome da valorização dessas palavras-chave portadoras de adesão. Políticos de grande habilidade oratória logram alinhavar esse conteúdo em um contexto razoavelmente conexo, 
resultando por vezes em belas peças discursivas. Já em outros casos, a aparente aleatoriedade das manifestações beira a esquizofrenia. Mas o resultado tem demonstrado ser superior ao da busca da posição de centro, em termos de sedução do eleitorado e captura de votos.

A técnica, contrariamente ao propalado, não é gratuita ou de custo inerentemente baixo, apenas sua composição de custos difere daquela subjacente à exploração da mídia eletrônica tradicional. É preciso mapear as pessoas em nível quase que individual e situá-las geograficamente nas redes sociais, para encaminhar mensagens personalizadas direcionadas por robôs. Complementar a essa técnica é o uso de mapeamento de vínculos nas redes sociais para identificação de pontos focais, os "internautas alfa", que concentrem clusters em seu entorno, que tenham um número expressivo de seguidores, que formem opiniões e que sejam capazes de operar as mensagens fragmentadas e selecionadas, repassando-as aos seus grupos de influência nas redes sociais ${ }^{6}$ (ORTELLADO, 2018).

\section{O fenômeno fake news}

A verdadeira força do uso de big data não consiste, portanto, na adequação do discurso político. A rede social e o app de comunicação tornam possível o acesso pessoal ao eleitor, em uma escala nunca experimentada. São milhões de pessoas que recebem, continuamente, uma sucessão de mensa-

\footnotetext{
6 A identificação desses clusters é particularmente relevante quando se faz uso de programas que propiciam uma comunicação estritamente privada, como o Whatsapp. A disseminação de mensagens passa a ter um componente de pessoa a pessoa mais relevante, complementando o uso de bots.
} 
gens personalizadas, ajustadas a suas características mais íntimas. $\bigcirc$ valor dessas mensagens não resulta de sua veracidade, da referência a fatos comprováveis ou de sua aproximação à plataforma do candidato. Seu valor resulta da aderência aos desejos e aos temores íntimos de cada receptor individual, ainda que sejam mensagens falsas ou mentirosas. E de fato o são: seu nome, fake news.

O teste em grande escala dessa técnica deuse nas eleições gerais de 2018 no Brasil. O uso de fake news por candidatos da coligação vencedora foi amplo e agressivo. A ferramenta foi aplicada em tal extensão que chamou a atenção do Tribunal Superior Eleitoral, levando a corte, que responde pela operacionalização das eleições, a emitir declarações ameaçadoras, ainda que inócuas, em vista das garantias constitucionais de liberdade de expressão vigentes no Brasil?.

O formato e conteúdo das fake news é muito diversificado e sua análise escapa aos objetivos deste texto. No entanto, entre as abordagens para a avaliação das mensagens, uma faz uso de big data e merece ser comentada. Trata-se do uso de regressões hedônicas ou de engajamento. O criador dessas mensagens segue uma receita em que alguns parâmetros são sistematicamente quantificados. A seleção dos parâmetros é uma estratégia de cada consultoria e pode incluir, por exemplo, métricas como tamanho

Ver, por exemplo, "Fux diz que Justiça pode anular uma eleição se resultado for influenciado por 'fake news' em massa", G1, 21 de junho de 2018; "TSE pode anular candidatura impulsionada por notícias falsas, diz Fux", O Estado de São Paulo, 22 de agosto de 2018; "Após quatro meses, conselho do TSE que discute fake news vai se reunir semana que vem", O Globo, 5 de outubro de 2018. 
da mensagem, uso de notícia veiculada, grau de humor, uso de imagem, uso de montagem, indicadores de semântica ou de exegese. Esses números são cruzados com as características psicométricas dos recipientes e suas reações, a exemplo dos likes e retweets. Desse modo, a relevância de cada parâmetro é quantificada e um progressivo refinamento da composição e distribuição das mensagens é alcançado. Como outras técnicas de big data, trata-se de uma análise prospectiva baseada em processamento computacional maciço.

No novo modelo de comunicação, em suma, a função contratual do discurso eleitoral fica inexoravelmente prejudicada, pois cada eleitor recebe uma versão individualizada e fragmentada dos compromissos de campanha ou de episódios politicamente irrelevantes, mas que compelem o eleitor a se sentir atraído pelo candidato. O discurso é construído de modo voltado ao reforço emocional. A função de sedução torna-se preponderante e a função de agregação centra-se na construção de mobilizações pontuais de apoio ${ }^{8}$.

Nesse ambiente, a estratégia vencedora será aquela que lograr mapear com maior exatidão as concentrações de eleitores com determinadas características psicométricas e sua localização exata nas redes virtuais. Uma vez escolhidas as características a serem atendidas por cada mensagem (e as variações

8 Destaque-se que o caráter fragmentário e abrangente dessa modalidade de comunicação individualizada representa um elemento do que Gerbaudo $(2014: 67,75)$ chama de ruptura na prática do ativismo na internet. Estudos anteriores à década atual (veja-se, por exemplo, a ótima resenha de AGGIO, 2010) ainda não capturavam essa transformação abrupta. 
são vastas), o produto "mensagem" é construído e disseminado seletivamente.

\section{Alguns resultados apontados na literatura}

\section{Efeitos do localismo na captura virtual do eleitor}

O problema do localismo da construção de opinião tem dois aspectos relevantes e, ao contrário da acepção tradicional, que associa localidade ao domicílio eleitoral do eleitor (vide, por exemplo, KEY, 1949, p. 302), relaciona-se à posição do eleitor nas comunidades virtuais.

O primeiro problema é o de que, contrariamente ao eleitor que se expõe à mídia tradicional com cobertura equilibrada, o usuário da rede social fica exposto a uma variedade limitada de informações e de estímulos para a construção de seu ambiente de recepção de mensagens. De fato, como nas redes sociais as pessoas tendem a estabelecer vínculos de acordo com laços sociais ou preferências preexistentes, há um viés de autosseleção do grupo em que cada um se coloca. Ouve-se e se lê mais do mesmo, ficando reforçados em nível local (e não de alcance de todo o público) os preconceitos existentes. Variar as fontes é um esforço além da disponibilidade de tempo do internauta (HOPIA, 2013, p. 44). Desse modo, em relação a vários candidatos, a informação não chega ao usuário: ou não é recebida, ou não é compreendida, ou não é aceita.

O segundo problema é o de que a interação no mundo virtual se tornou um substituto da vivência social no mundo real. Fazemos compras pelo e-bay ou pelo Mercado Livre, escolhemos livros pela Amazon 
ou BN, acompanhamos notícias pelo Twitter, trocamos confidências pelo Whatsapp ou pelo Snapchat, deixamos o curriculum no Linkedln, buscamos amigos pelo Facebook, só para citar alguns dos muitos apps que orientam nossa vida social. A interação nesses ambientes provê uma ilusão de privacidade e de inexistência de reações contundentes às atitudes e ao linguajar. Desse modo, os usuários tendem a exibir um grau de agressividade que, na vida real, não exercitam. Isto resulta em reações de confronto ou de censura em nível local que reprimem o debate e o exame analítico das implicações das escolhas eleitorais ou até resultam em franca inimizade, embora essas atitudes sejam, não raro, estratégicas (BALOCCO, 2016, p. 513-514; GAUMONT et al, 2018, p. 25).

\section{Efeitos sobre a relevância da intermediação institucional}

Nos últimos anos, essa formatação da campanha eleitoral vem resultando na desconstrução do partido político como instituição representativa do eleitorado. De fato, a maior parte dos partidos está vinculada a um discurso político-ideológico que tem raízes históricas e do qual não é fácil desfazer-se. Ademais, suas posições refletem os interesses da burocracia partidária e dos intelectuais orgânicos vinculados ao partido, existindo uma inércia interna para sua revisão. Com isso, as campanhas de maior sucesso decorreram de grupos ou siglas apartidárias, de tendências intrapartidárias ou de aglomerações informais que coordenaram suas estratégias.

Assim, as mensagens tendem a pender para 0 pragmatismo e para a desconstrução do discurso político. Nas palavras de Marcos Peña, estrategista da 
aliança Cambiemos, agremiação que levou Mauricio Macri à presidência da Argentina, "não viemos com um manual de ideologia, mas para melhorar a vida das pessoas". Sua convicção, alinhada com a de Duran Barba, marqueteiro equatoriano a serviço de Macri, é de que o macrismo deve preservar a ideia de ser algo novo, "na teoria, nem de direita, nem de esquerda, nem estatista, nem liberal, nem peronista, nem radical" (CIBEIRA, 2017, p. 9, 100-101).

A construção do relacionamento entre candidato e público pelo canal das mídias sociais e dos apps de comunicação descarta as camadas de organização subsequentes e se concentra na abordagem direta ao eleitorado. Desse modo, torna-se desnecessária a negociação de interesses com a sociedade organizada e a construção de uma organicidade do discurso político, dada pela intermediação partidária. Essas dimensões surgirão a posteriori, na medida das necessidades, ao longo da condução da prática governamental. Na campanha, são descartáveis ou meramente acessórias. Isto resulta na possibilidade de desconstrução do partido político como instituição representativa, ao menos no embate eleitoral?. Outro efeito importante dessa estratégia tem sido o esvaziamento do centro político e a consolidação de núcleos de interesse no entorno das figuras míticas dos candidatos (QUIROGA, 2018, p. 75).

9 Há, no entanto, episódios de criação de novas siglas partidárias de forte base telecomunicativa, que se esforçam em combinar uma orientação ideológica definida com o uso eficaz da fragmentação da mensagem característica da comunicação pelas redes sociais, a exemplo do Movimento 5 Stelle (M5S) na Itália e dos partidos Novo e Podemos no Brasil, agregando complexidade a esse quadro (ver, por exemplo, GERBAUDO, 2014). 


\section{Influência política dos provedores de aplicação}

Diante da pulverização do espaço informacional destinado ao público, os operadores de redes sociais, como Facebook, Snapchat e Linkedln, os provedores de informações, como Twitter e Google, os provedores de comunicação interpessoal, como Whatsapp, tendem a se colocar como intermediários passivos dos relacionamentos em rede que hospedam. No entanto, esse posicionamento é enganoso.

Sua intermediação tem valor informacional para os candidatos. O fornecimento de bases de dados de usuários e o mapeamento de suas conexões são oferecidos por esses provedores mediante remuneração. A formação de grupos e a disseminação de mensagens em grande escala são também objeto de contratos específicos. Esses recursos estão vedados aos usuários "normais", que se associam às redes gratuitamente ${ }^{10}$, justamente porque são objeto de contratação específica e integram o mix de receitas do provedor. Em certos casos, o provedor poderá exercer essa oferta em termos assimétricos, calibrando os pacotes de dados fornecidos, negociando contratos suplementares ou assegurando acesso não remunerado a certos lotes de dados ${ }^{11}$.

10 A ideia de gratuidade, nesse caso, é enganosa. Os termos de adesão asseguram ao provedor uma série de controles e permitem que este comercialize determinadas informações do usuário. Desse modo, a licença é uma forma indireta de pagamento pela adesão à rede.

11 Observe-se, que essa possibilidade dever ser qualificada. Os provedores são globais e podem ser obrigados, por determinação da legislação local, a reforçar mecanismos de privacidade, bloqueando acessos, ou, em sentido inverso, a assegurar a navegação em suas redes a determinados órgãos de segurança ou auditoria de outros países, terceirizando alguns de seus dados. 
Os procedimentos praticados por cada rede social estão usualmente especificados com clareza em seus termos de uso, nas políticas de privacidade e nos portfolios de serviços remunerados à disposição do mercado. São documentos que os usuários em geral se omitem de ler. A realidade, em termos de internet, é que os dados pessoais transitam com relativa facilidade na rede e são complementados por informações psicométricas que as pessoas sequer imaginam que foram coletadas e adicionadas. Não é exagero afirmar que sabem sobre nós coisas que nós mesmos não somos capazes de saber.

As consultorias de estratégia usam essas informações e recursos comercializados pelos provedores de redes sociais para ajustar as mensagens aos receptores e para fazer a distribuição eficiente das mesmas, em uma tentativa de maximizar, a custos competitivos, os efeitos de adesão ao candidato e de blindagem contra a comunicação do adversário.

A relação entre equipes de campanha, consultorias especializadas em análise de dados e provedores de aplicação tornou-se, em suma, um ativo essencial para uma campanha eleitoral bem operacionalizada.

\section{Considerações finais}

Este artigo tem um caráter prospectivo e compila conjecturas que já se encontram disponíveis a respeito da condução de campanhas eleitorais vitoriosas nos últimos anos. Em alguns casos, como o da eleição de Donald Trump nos EUA em 2016 e de Jair Bolsonaro no Brasil, em 2018, tem-se a impressão de que um azarão alcançou o poder de modo acidental, em decorrência de uma combinação de fatores fortuitos.

Trata-se de uma impressão ilusória. Em ambos os casos, e em casos de outros candidatos que che- 
garam competitivamente ao final da campanha, embora não a tenham vencido, houve uma intensa atividade de retaguarda, conduzida por meses seguidos, para a construção da personagem e da sua ligação a eleitores, fundamentada em técnicas de big data. A competitividade dessas técnicas, em relação às campanhas feitas pela mídia eletrônica tradicional, resulta da capacidade que propiciam de discriminação individualizada dos eleitores e de acesso diferenciado a cada um.

Uma questão em aberto é a avaliação de uma persistência desses efeitos. Não se sabe, ainda, se decorrem da construção que a técnica proporciona ou apenas de uma assimetria entre abordagens, na medida em que outros candidatos ainda privilegiam campanhas calcadas na exposição midiática tradicional. Talvez o nivelamento do jogo dissolva parte dos efeitos que no momento são observados.

Existe, em suma, uma agenda de pesquisa a ser enfrentada, que deverá evoluir na medida em que mais indicadores dos pleitos eleitorais recentes venham a ser levantados.

É importante apontar, enfim, que este texto deu destaque a um aspecto que serve de mecanismo para conduzir a mudança política: a transformação dos processos comunicacionais usados pelos candidatos. No entanto, o desenho total da transformação política decorrente do pleito eleitoral é muito mais complexo e requer tanto a mudança de valores e de visões dos grupos sociais quanto o reequilíbrio de forças de grupos de interesse. Requer, sobretudo, um ambiente de crise que traga prejuízos a vários desses interesses: será nesse ambiente que 
as forças de mudança encontrarão espaço para se desenvolver.

\section{Referências}

AGGIO, Camilo. "Campanhas online: o percurso de formação das questões, problemas e configurações a partir da literatura produzida entre 1992 e 2009". Opinião Pública, 16 (2), p. 426-445. 2010.

BACHRACH, Yoram, Michal KOSINSKI, Thore GRAEPEL, Pushmeet KOHLI e David STILLWELL. "Personality and patterns of Facebook usage". ACM Web Science Conference. Proceedings of the ACM Web Science Conference, pp 36-44. 2012.

BAGDIKIAN, Ben H. The Media Monopoly. Boston: Beacon Press. $6^{a}$ ed., 2000.

BALOCCO, Anna E. "O flaming (ou violência verbal em mídia digital) e suas funções na esfera pública". Linguagem em (Dis)curso, 16 (3), p. 503-521, setembro/dezembro de 2016.

BEZERRA, Ada G. e Fábio R. da SILVA. "O marketing político e a importância da imagem-marca em campanhas eleitorais majoritárias". Biblioteca On-line de Ciências da Comunicação, 2006. In: http:// www.bocc.ubi.pt/pag/silva-fabio-marketing-politico-imagem.pdf.

BIMBER, Bruce. "Digital media in the Obama campaigns of 2008 and 2012: adaptation to the personalized political communication environment". Journal of Information Technology \& Politics, 11, p. 130-150, 2014.

BOAS, Taylor C. "Television and neopopulismin Latin America: media effects in Brazil and Peru". Latin American Research Review, 40 (2), p. 27-49, 2005.

CASSWELL, Mark (texto). TV Guide: Fifty Years of Television. Nova York: Crown Publishers. 2002.

CHADWICK, Andrew e Jennifer STROMER-GALLEY. "Digital media, power, and democracy in parties and election campaigns: party decline or party renewal?". International Journal of Press/Politics, 21 (3), p. 283-293, 2016. 


\section{CIBEIRA, Fernando. Macristocracia: la Historia de las Familias que}

Gobiernan la Argentina. Buenos Aires: Planeta, 2017.

COHEN, Richard M. "The corporate takeover of news: blunting the sword". In: BARNOUW, Erik et al (orgs.). Conglomerates and the media. Nova York: The News Press, 1997.

DIMMICK, John, Yan CHEN e Zhan LI. "Competition between the Internet and traditional news media: the gratification-opportunities niche dimension". Journal of Media Economics, 17 (1), p. 19-33, 2004.

DOWNS, Anthony. "An economic theory of political action in a democracy". Journal of Political Economy, 65 (2), p. 135-150, 1957.

EDWARDS, Brian T. "Trump, from reality TV to twitter, or the selfie-determination of nations". Arizona Quarterly, 74 (3), p. 25-45, outono de 2018.

FILER, Tanya e Rolf FREDHEIM. "Popular with the robots: accusation and automation in the Argentine presidential elections, 2015". International Journal of Politics, Culture and Society, 30, p. 259-274, 28 de julho de 2016.

GAUMONT, Noé, Maziyar PAHAHI e David CHAVALARIAS. "Reconstruction of the socio-semantic dynamics of political activist Twitter networks - Method and application to the 2017 French presidential election". PLOS ONE, 13 (9): e0201879, 2018.

GERBAUDO, Paolo. "Populism 2.0: social media activism, the generic Internet user and interactive direct democracy". In: TROTTIER, Daniel e Christian FUCHS (orgs.). Social Media, Politics and the State. Nova York: Routledge, 2014, pp. 67-87.

GOIDEL, Robert K. e Todd G. SHIELDS. "The vanishing marginals, the bandwagon, and the mass media". Journal of Politics, 56 (3), p. 802810, agosto de 1994.

GOMES, Wilson, Breno FERNANDES, Lucas REIS e Tarcizio SILVA. "Politics 2.0: a campanha on-line de Barack Obama em 2008". Revista de Sociologia e Política, 17 (34), p. 29-43.

GRABER, Doris A. (org.). Media Power in Politics. Washington: CQ Press, 2000. 
GRASSEGER, Hannes e Mikael KROGERUS. "A manipulação da democracia através do big data". Jornal CGN, 6 de fevereiro de 2017.

HENDRICKS, John A. e Robert E DENTON Jr. "Political campaigns and communicating with the electorate $n$ the twenty-first century". In: HENDRICKS, J.A e R.E DENTON Jr. (orgs.). Communicator-in-Chief: How Barack Obama Used the New Media Technology to Win the White House. Plymouth: Lexington Books, 2010, pp. 1-18.

HOPIA, Henna. "Decline of the media? Decline of democracy?". European View, 12 (1): 41-49, junho de 2013.

HUNTEMANN, Nina. "The effects of telecommunication reform on US commercial radio". In: LEWIS, Justin e Toby MILLER. Critical Cultural Policy Studies: a Reader. Oxford: Blackwell, 2003.

ITUASSU, Arthur, Sérgio LIFSCHITZ, Daniel SCHWABE, Letícia CAPONE e Vivian MANNHEIMER. "Campanhas online e democracia: uma proposta de pesquisa para as eleições de 2018 no Brasil". Artigo apresentado no $1^{\circ}$ Congresso do INCT.DD, setembro de 2018.

JAGDEV, Gagandeep, Amandeep KAUR e Amandeep KAUR. "Excavating big data associated to Indian elections scenario via Apache Hadoop". International Journal of Advanced Research in Computer Science, 7 (6), p. 117-123, novembro de 2016.

JOHNSON, Shontavia J. "Donald Trump, disruptive technologies, and Twitter's role in the 2016 American presidential campaign". Widener Commonwealth Law Review, 27, p. 39-82, 2018.

JONES, RonNell A. e Sonja R. WEST. "The fragility of the free American press". Northwestern University Law Review, 47, p. 567-595, 2017.

KEY Jr., Valdimer O. Southern Politics in State and Nation. Edição revista e ampliada. Knoxville: University of Tennessee Press, 1984 ( $1^{a}$ ed.: 1949).

KOSINSKI Michal, David STILLWELL e Thore GRAEPEL. "Private traits and attributes are predictable from digital records of human behavior". Proceedings of the National Academy of Sciences - PNAS, 110 (15), p. 5802-5805, abril de 2013.

KOUSSER, J. Morgan. "Restoring politics to political history". In: ROTBERG, Robert I. Politics and Political Change. Cambridge (MA): MIT Press, 2001, pp. 19-45. 
MORAES, Dênis de. "A comunicação sob o domínio dos impérios multimídias". In:

DOWBOR, Ladislau et al. (orgs.) Desafios da Comunicação. Petrópolis: Vozes, 2000.

ORTELLADO, Pablo. "O Whatsapp nas eleições". Folha de São Paulo, 98 (32.752): A2. Opinião. 4 de dezembro de 2018.

PERSILY, Nathaniel. "Can democracy survive the internet?". Journal Of Democracy, 28 (2), p. 63-76, abril de 2017.

PERSSON, Torsten e Guido TABELLINI. Political Economics: Explaining Economic Policy. Cambridge (MA): MIT Press, 2000.

QUIROGA, Hugo. "Los caminos de la democracia en el siglo XXI: los escenarios en América latina". Società/Mutamento/Politica, 9 (17), p. 69-86, 2018.

RENNÓ, Lúcio R. "O dilema do rico: número de candidatos, identificação partidária e accountability nas eleições de 2002 para a Câmara dos Deputados". In: SOARES, Gláucio A. e Lúcio R. RENNÓ (orgs.). Reforma Política: Lições da História Recente. Rio: Ed. FGV, 2006, pp. 47-68.

RODRÍGUEZ-ANDRÉS, Roberto. "Trump 2016: ¿̇presidente gracias a las redes sociales?". Palabra Clave, 21 (3), p. 831-859, setembro de 2018. 